\title{
Travelling for radiation cancer treatment: Patient satisfaction
}

\author{
By Margaret I. Fitch, Ross E. Gray, Tom McGowan, \\ Ian Brunskill, Shawn Steggles, Scott Sellick, \\ Andrea Bezjak and Donna McLeese
}

\section{Abstract}

This study was conducted for the purpose of describing cancer patients' satisfaction with their care when they had to travel unexpectedly away from home for treatment. Ontario initiated a rereferral program for cancer patients who needed radiation therapy when the waiting lists in southern Ontario became lengthy. Patients travelled to the United States or northern Ontario for their care. A standardized survey containing 25 items with five-point Likert scale responses was mailed to all patients who participated in the rereferral program, following completion of their treatment. Items covered patient experiences before leaving home, in preparing for travel, and staying at the cancer facilities away from home. A total of $466(55.8 \%)$ patients returned the survey. Overall, patients were satisfied with their care. However, there were a number of areas identified by patients where improvements could be made. These areas included access to support prior to leaving home, access to information about supportive care services while away from home, and sensitivity to personal needs in making arrangements for travel. Provision of information and support are important to cancer patients having to travel for cancer treatment.

A cancer diagnosis and its resultant treatment have an impact on an individual that is more than physical. The impact may be felt emotionally, socially, psychologically, spiritually, or practically (Carroll-Johnson, Gorman \& Bush, 1998). Changes that occur as a result of this impact may evoke a myriad of challenges and coping with these challenges can be difficult for both the individual and his or her family members (Abbey-Livingston and Associates, 1990; Canadian Cancer Society, 1992).

The nature of radiation treatment for cancer demands that patients attend the treatment facility on a daily basis for four to five weeks. Patients who live a distance from the treatment facility and who are unable to drive on a daily basis, may have to be away from home for that period of time and stay in accommodations close to the cancer centre. Being away from home during the treatment interval has the potential to add to the distress an individual may be feeling, particularly if this travel is unexpected.

In 1999, it became apparent that, for various reasons, several cancer treatment centres in southern Ontario were unable to provide radiation treatment in a timely fashion for all patients requiring it. Patients who would normally have been able to stay at home during the treatment interval were re-referred to cancer treatment centres in northern Ontario or the United States. A formal re-referral program was organized to re-refer selected patients to a location agreed upon by the patients from a predetermined list and to assist patients with travel and accommodation arrangements. Expenses associated with travelling to another centre were reimbursed as part of this program.

Little systematic study of patient perspectives about travelling for cancer treatment has been reported. Given, Given and Harlan (1994) described geographic isolation as one of the factors influencing access to cancer care for individuals living in rural Michigan. When cancer care services are not available locally, the rural population of Michigan is often excluded from state-of-the-art adjuvant therapy that requires weekly or daily visits to a treatment facility. Rural Australians are also geographically isolated and confront issues of having to travel long distances, especially for specialist care (McGrath et al., 1999a). When cancer patients have to travel for treatment, they describe experiencing concerns about arrangements for family and work responsibilities, worry over how the family will manage while they are away, and financial burdens (Davis \& Girgis, 1998; McGrath et al., 1999b).

To date, one Canadian study has focused on the burden of travel for cancer patients receiving radiation treatment (Fitch et al., 2003). In this Canadian study, three groups of breast and prostate cancer patients were interviewed: a) patients who were unexpectedly re-referred away from home to northern Ontario or the United States for treatment, b) patients who remained at home during treatment, and c) patients who lived in northern Ontario and travelled distances comparable to those in the first group as a normal course of events. The findings revealed that cancer patients experience difficulties with travelling for treatment regardless of whether it was an expected or unexpected event. For those who stay in a hotel or residence near the cancer centre, the interactions with peers are of great importance in helping them cope with the situation.

The Ontario Re-referral Program was established as a provincial program at a time when the waiting period for radiation therapy was deemed unacceptable by radiation oncologists at several southern Ontario cancer treatment centres. Arrangements were made with two Canadian cancer treatment centres (Sudbury and Thunder Bay) and five centres in the United States (Buffalo - two sites, Cleveland, Rochester and Detroit) for patients to receive radiation treatment. A central office was established for coordination of the re-referrals. Breast cancer and prostate cancer patients were given the option, through dialogue with their physician or surgeon, of being re-referred for treatment at a cancer centre away from home or waiting to receive treatment at the cancer clinic nearest their home. If they chose the option of being re-referred, the central re-referral office staff then made the arrangements for the patient to travel to that centre for care, to stay in a designated hotel, and to receive reimbursement for travel, food, and accommodation. Prior to their travelling, most patients did

Margaret I. Fitch, PhD, Psychosocial and Behavioural Research Unit, Toronto Sunnybrook Regional Cancer Centre, Coordinator, Supportive Care, Cancer Care Ontario.

Ross E. Gray, PhD, Psychosocial and Behavioural Research Unit, Toronto Sunnybrook Regional Cancer Centre.

Tom McGowan, MD, FRCPC, Cancer Care Ontario.*

Ian Brunskill, MBA, CHE, Cancer Care Ontario.*

Shawn Steggles, PhD, Northeastern Ontario Regional Cancer Centre.*

Scott Sellick, PhD, Northwestern Ontario Regional Cancer Centre. Andrea Bezjak, MD, FRCPC, Princess Margaret Hospital.

Donna McLeese, $R T(T)$, Cancer Care Ontario.*

* at time of study 
not interact with a radiation oncologist or staff from a local cancer centre. If the patient elected to remain at home and to be treated at the cancer centre nearby, they went on the waiting list for treatment at that cancer centre. Subsequently, they did not receive reimbursement for any expenses associated with their treatment.

This study was conducted for the purpose of describing patients' satisfaction with their care during their involvement with unexpected travel away from home for radiation cancer treatment. It was anticipated that the investigation would help identify strategies that could be implemented to meet needs identified by patients as relevant in this situation. This article presents data gathered during the 12 months following the implementation of the Ontario Re-referral Program. It presents an approach and assessment tool that may be of use to other cancer programs that may have to send patients to other locations for radiation treatment.

\section{Methods}

This study utilized a survey to capture patients' satisfaction with their care during their experiences of being re-referred for cancer radiation treatment. Ethics approval was given by the Research Ethics Committee of Sunnybrook and Women's College Health Sciences Centre.

The sample for this investigation included all cancer patients who were selected as part of the re-referral program to travel to a cancer centre away from their home city for radiation treatment. The eligibility criteria for the re-referral program included: 1) diagnosed with breast or prostate cancer, and 2) requiring radiation treatment as first line therapy unless one of the following conditions existed: neurological compromise, morbid intercurrent illness, distant metastases, tracheostomy/gastrostomy/jejunostomy/nephrostomy

Table One. Re-Referral program patient satisfaction:

Items about cancer treatment centre nearest patient's home prior to travel (quarterly and full samples)

\begin{tabular}{|c|c|c|c|c|c|}
\hline Part 1 Items & $\begin{array}{c}\text { Apr - June } 1999 \\
(n=98)\end{array}$ & $\begin{array}{l}\text { July-Sept } 1999 \\
(n=121)\end{array}$ & $\begin{array}{c}\text { Oct-Dec } 1999 \\
(n=164)\end{array}$ & $\begin{array}{c}\text { Jan-Mar } 2000 \\
(\mathbf{n}=83)\end{array}$ & $\begin{array}{c}\text { Total } \\
(n=466)\end{array}$ \\
\hline \multicolumn{6}{|c|}{$\begin{array}{l}\text { Proportion of respondents in each group } \\
\text { who agreed with statement }\end{array}$} \\
\hline $\begin{array}{l}\text { 1. Prior to my first visit to the cancer } \\
\text { treatment centre nearest my home, } \\
\text { I received timely and useful } \\
\text { information about what to expect. }\end{array}$ & $68 \%$ & $76 \%$ & $68 \%$ & $71 \%$ & $73 \%$ \\
\hline $\begin{array}{l}\text { 2. The registration procedure at the } \\
\text { cancer treatment centre nearest my } \\
\text { home was straightforward. }\end{array}$ & $90 \%$ & $88 \%$ & $86 \%$ & $81 \%$ & $87 \%$ \\
\hline $\begin{array}{l}\text { 3. Staff at the cancer treatment centre } \\
\text { was courteous and respectful. }\end{array}$ & $96 \%$ & $92 \%$ & $92 \%$ & $96 \%$ & $94 \%$ \\
\hline $\begin{array}{l}\text { 4. During my initial visit, I was given } \\
\text { a full explanation of my medical } \\
\text { condition and treatment options. }\end{array}$ & $85 \%$ & $86 \%$ & $80 \%$ & $81 \%$ & $83 \%$ \\
\hline $\begin{array}{l}\text { 5. It was clear to me that the decision } \\
\text { to travel to another city for radiation } \\
\text { treatment was my own, and that } \\
\text { I had the right to refuse. }\end{array}$ & $95 \%$ & $90 \%$ & $88 \%$ & $86 \%$ & $90 \%$ \\
\hline $\begin{array}{l}\text { 6. During my initial appointment, I felt } \\
\text { that I had all the time I needed to } \\
\text { discuss the issues of importance } \\
\text { to me. }\end{array}$ & $88 \%$ & $84 \%$ & $85 \%$ & $80 \%$ & $85 \%$ \\
\hline $\begin{array}{l}\text { 7. I received all the information I needed } \\
\text { about the steps required to arrange } \\
\text { my radiation in another city. }\end{array}$ & $87 \%$ & $89 \%$ & $76 \%$ & $70 \%$ & $82 \%$ \\
\hline $\begin{array}{l}\text { 8. I felt that I had access to physicians } \\
\text { and nurses if I required, during the } \\
\text { time prior to my leaving for } \\
\text { another city. }\end{array}$ & $64 \%$ & $75 \%$ & $66 \%$ & $73 \%$ & $69 \%$ \\
\hline $\begin{array}{l}\text { 9. I felt well supported by health } \\
\text { professionals at the cancer treatment } \\
\text { centre nearest my home between the } \\
\text { time of my diagnosis and when I } \\
\text { started my radiation treatment. }\end{array}$ & $70 \%$ & $74 \%$ & $64 \%$ & $76 \%$ & $70 \%$ \\
\hline $\begin{array}{l}\text { 10. I felt confident that the medical team } \\
\text { at the cancer treatment centre nearest } \\
\text { my home would provide high quality } \\
\text { follow-up care when I returned from } \\
\text { the city where I received radiation } \\
\text { treatment. }\end{array}$ & $74 \%$ & $70 \%$ & $75 \%$ & $72 \%$ & $73 \%$ \\
\hline
\end{tabular}


tube, special oxygen requirements, concurrent cancer therapy (i.e., chemotherapy), need for specialized multidisciplinary treatment, nonEnglish speaking, primary caregiver for small children or other family member, and less than 21 years of age.

Patients were accrued by letter at the end of their radiation treatment after they had completed their course of therapy at the cancer centre away from home. Packages were mailed to all patients who had been re-referred. The packages contained a letter of explanation and invitation to participate in the study, a copy of the satisfaction survey, and a pre-stamped return envelope. Patients who did not return the survey within a month were contacted once by telephone as a reminder. A second package was mailed to those who had misplaced the first envelope and still wanted to participate in the survey.

A total of 907 surveys were mailed during the first 12 months of the re-referral program and 466 were returned (55.8\% response rate).

Satisfaction survey: The Re-referral Satisfaction Survey was developed for use in this study. The survey was designed to elicit patients' satisfaction with events prior to and during their radiation treatment. The experiences covered in the survey questions included Part 1) initial visits to the cancer centre nearest their home (10 questions), Part 2) preparation for travel away from home (three questions), and Part 3) visits to the cancer centre away from home (12 questions). The specific questions covered issues concerning access to information, registration procedures, travel arrangements, accommodations away from home, communication with staff members, access to support services, and confidence in care. All questions were close-ended and asked patients to indicate their agreement or disagreement on a five-point Likert-type scale. The response options for all questions were strongly agree, agree, neutral, disagree, and strongly disagree, in addition to a non-applicable option. The non-applicable option was included because some of the patients would not have had a visit to a cancer centre near their home prior to being re-referred to another cancer centre. Face validity of the survey was determined by having three experts in the care of radiation patients review the items.

\section{Analysis}

The analysis of the satisfaction data was descriptive. Patients were grouped together on the basis of three-month intervals based on when they travelled for radiation treatment. Given that travelling in Canadian winters might present more challenges than at other times of the year, it was helpful to review data in quarterly groupings. The frequency of responses for each of the questions was calculated for each three-month interval (April-June $n=98$; July-September $n=121$; October-December $n=164$; January-March $n=83$ ) as well as the total sample ( $\mathrm{N}=466)$. Subsequently, analysis was conducted with the total sample to determine if there were significantly different proportions of patients expressing satisfaction with each item based on gender (male/female) and geographic site of treatment (Canada/United States). Chi-squared analysis was applied in each case with a significance level of $\mathrm{p}=0.05$.

\section{Results}

Sample

A total of 466 patients returned the satisfaction survey. The average age of the respondents was 65.6 years (standard deviation $=$ 8.1). Fifty-eight per cent $(n=296)$ of the respondents were female. Seventy-two per cent $(n=364)$ had been re-referred to the United States for radiation treatment while the remainder travelled to northern Ontario.

\section{Satisfaction with care prior to travelling away from home}

The proportions of respondents who indicated satisfaction with aspects of their care prior to travelling away from home are represented in Table One. Overall, the patients who attended a cancer centre close to their home before they decided to travel, the majority indicated they were satisfied with their care. Patients agreed that staff in the cancer centre closest to their home was courteous and respectful $(94 \%)$ and that it was clear to them the decision to travel away from home was their own (90\%). Between the time of diagnosis and starting radiation treatment away from home, patients felt they had access to physicians and nurses $(69 \%)$ or felt supported by staff at the cancer centre nearest their home $(70 \%)$. About three-quarters of the patients $(73 \%)$ felt confident in the follow-up care the staff at that cancer centre would provide upon the patient's return home $(73 \%)$.

In general, the proportions of patients who were satisfied with their care at the cancer centre nearest their home remained relatively consistent over the course of the 12-month timeframe. The one notable decrease ( $87 \%$ to $70 \%$ ) occurred for the item about receiving information regarding the steps required to arrange radiation in another city. Although not as dramatic, there were also decreases in the proportion of patients who were satisfied with the registration procedures at the cancer centre nearest their home (90\% to $81 \%$ ), the amount of time they had to discuss issues of importance $(88 \%$ to $80 \%$ ), and the explanation the patients received about their medical condition and treatment options (85\% to $81 \%)$.

\section{Satisfaction with co-ordination of arrangements for travelling}

The proportions of patients who were satisfied with the coordination of their arrangement to travel to another cancer centre

Table Two. Re-Referral program patient satisfaction:

Items about coordination of travel to city where radiation treatment was received (quarterly and full samples)

\begin{tabular}{|c|c|c|c|c|c|}
\hline Part 2 Items & $\begin{array}{c}\text { Apr - June } 1999 \\
(n=98)\end{array}$ & $\begin{array}{l}\text { July-Sept } 1999 \\
\quad(n=121)\end{array}$ & $\begin{array}{l}\text { Oct-Dec } 1999 \\
(n=164)\end{array}$ & $\begin{array}{c}\text { Jan-Mar } 2000 \\
(n=83)\end{array}$ & $\begin{array}{c}\text { Total } \\
(n=466)\end{array}$ \\
\hline & \multicolumn{5}{|c|}{$\begin{array}{l}\text { Proportion of respondents in each group } \\
\text { who agreed with statement }\end{array}$} \\
\hline $\begin{array}{l}\text { 11. The arrangements for my travelling } \\
\text { to receive radiation treatment in } \\
\text { another city were made in a timely } \\
\text { and efficient manner. }\end{array}$ & $90 \%$ & $90 \%$ & $75 \%$ & $68 \%$ & $81 \%$ \\
\hline $\begin{array}{l}\text { 12. The person who helped arrange my } \\
\text { trip was courteous and respectful. }\end{array}$ & $95 \%$ & $97 \%$ & $91 \%$ & $87 \%$ & $93 \%$ \\
\hline $\begin{array}{l}\text { 13. My needs and those of my family/ } \\
\text { friends were taken into account when } \\
\text { arrangements were being made to } \\
\text { travel to another city. }\end{array}$ & $81 \%$ & $83 \%$ & $70 \%$ & $71 \%$ & $76 \%$ \\
\hline
\end{tabular}


for their radiation treatment are presented in Table Two. The proportions of patients who were satisfied decreased over time across all three items regarding coordination. The most dramatic decrease occurred for the item concerning the timeliness and efficiency of making arrangements (90\% to 68\%). Overall, threequarters $(76 \%)$ of the respondents felt their needs and those of their families had been taken into account when the arrangements were being made.

\section{Satisfaction with care at cancer centre away from home}

The proportions of patients who were satisfied with aspects of their care at the cancer centre away from home are presented in Table Three. Overall, patients were satisfied with many aspects of care away from home. The aspects of care with which fewer patients were satisfied included the financial burden imposed by travelling away from home $(56 \%)$, being informed about supportive care services $(71 \%)$, and receiving timely and useful information about the cancer treatment centre prior to travelling there for treatment $(79 \%)$. Concerns about financial burden and supportive care services were evident across the entire 12-month period, while receiving information about the cancer treatment centre was more of an issue toward the end of the 12 months.

\section{Satisfaction by gender}

The proportions of female and male respondents indicating satisfaction with their care were compared using Chi-square analysis. The only four items for which there were significant differences concerned: 1) being clear that the decision to travel was the patients' own decision, 2) receiving the information needed to make arrangements to travel, 3) taking the patient and family needs into

Table Three. Re-Referral program patient satisfaction: Items about cancer treatment centre where radiation treatment was provided (quarterly and full samples)

\begin{tabular}{|c|c|c|c|c|c|}
\hline Part 3 Items & $\underset{(n=98)}{\text { Apr - June } 1999}$ & $\begin{array}{l}\text { July-Sept } 1999 \\
(n=121)\end{array}$ & $\begin{array}{c}\text { Oct-Dec } 1999 \\
(n=164)\end{array}$ & $\begin{array}{c}\text { Jan-Mar } 2000 \\
(\mathbf{n}=83)\end{array}$ & $\begin{array}{c}\text { Total } \\
(n=466)\end{array}$ \\
\hline \multicolumn{6}{|c|}{$\begin{array}{l}\text { Proportion of respondents in each group } \\
\text { who agreed with statement }\end{array}$} \\
\hline $\begin{array}{l}\text { 14. Prior to my first visit, I received } \\
\text { timely and useful information about } \\
\text { the cancer treatment centre where } \\
\text { I received radiation treatment. }\end{array}$ & $81 \%$ & $85 \%$ & $79 \%$ & $72 \%$ & $79 \%$ \\
\hline $\begin{array}{l}\text { 15. The registration procedure at the } \\
\text { cancer treatment centre was } \\
\text { straightforward. }\end{array}$ & $99 \%$ & $98 \%$ & $97 \%$ & $99 \%$ & $98 \%$ \\
\hline $\begin{array}{l}\text { 16. Staff at the cancer treatment centre } \\
\text { where I received radiation treatment } \\
\text { was courteous and respectful. }\end{array}$ & $100 \%$ & $100 \%$ & $100 \%$ & $100 \%$ & $100 \%$ \\
\hline $\begin{array}{l}\text { 17. I was happy with the amount of } \\
\text { information I was provided about } \\
\text { my radiation treatment. }\end{array}$ & $91 \%$ & $96 \%$ & $94 \%$ & $98 \%$ & $94 \%$ \\
\hline $\begin{array}{l}\text { 18. I was informed about services I might } \\
\text { need or desire, such as clinical } \\
\text { nutritionists, social workers, } \\
\text { pharmacists, chaplains, psychologists, } \\
\text { or support groups. }\end{array}$ & $67 \%$ & $71 \%$ & $68 \%$ & $76 \%$ & $71 \%$ \\
\hline $\begin{array}{l}\text { 19. I received excellent care at the cancer } \\
\text { centre where I received radiation } \\
\text { treatment. }\end{array}$ & $99 \%$ & $100 \%$ & $99 \%$ & $98 \%$ & $99 \%$ \\
\hline 20. My accommodations were excellent. & $95 \%$ & $86 \%$ & $90 \%$ & $98 \%$ & $91 \%$ \\
\hline $\begin{array}{l}\text { 21. It was easy to get to the treatment } \\
\text { centre from where I was staying. }\end{array}$ & $100 \%$ & $97 \%$ & $99 \%$ & $96 \%$ & $98 \%$ \\
\hline $\begin{array}{l}\text { 22. I had lots of support from health } \\
\text { professionals. }\end{array}$ & $95 \%$ & $92 \%$ & $94 \%$ & $91 \%$ & $92 \%$ \\
\hline $\begin{array}{l}\text { 23. Staff was sensitive to the fact that } \\
\text { I was living away from home and } \\
\text { might have special needs. }\end{array}$ & $88 \%$ & $91 \%$ & $91 \%$ & $91 \%$ & $91 \%$ \\
\hline $\begin{array}{l}\text { 24. Having my treatment in another city } \\
\text { did not cause me or my family any } \\
\text { extra financial burden. }\end{array}$ & $64 \%$ & $58 \%$ & $56 \%$ & $57 \%$ & $56 \%$ \\
\hline $\begin{array}{l}\text { 25. Based on my experience, I would } \\
\text { recommend the cancer centre where } \\
\text { I received radiation treatment to } \\
\text { family or friends if they needed } \\
\text { treatment. }\end{array}$ & $98 \%$ & $98 \%$ & $95 \%$ & $100 \%$ & $96 \%$ \\
\hline
\end{tabular}


consideration when travel was arranged, and 4) being informed about supportive care services. Fewer women than men indicated satisfaction with these items (see Table Four).

\section{Satisfaction by treatment setting}

The proportions of respondents who were satisfied with care in Canadian centres were compared with those in United States centres. Only one item revealed a significant difference in proportions. Eighty-four per cent of patients treated in Canadian centres were satisfied with the information they received about supportive care services while $66 \%$ were satisfied in U.S. centres $(\mathrm{df}=1, \mathrm{Chi}=8.64$, $\mathrm{P}=0.005)$.

\section{Discussion}

This study was undertaken to monitor the satisfaction with care of cancer patients who had to travel away from home for radiation treatment. Accepting re-referral meant that patients had to travel to another city for the duration of their radiation treatment. Those who travelled to northern Ontario were travelling by plane approximately $400 \mathrm{~km}$ to Sudbury and 1,400 km to Thunder Bay. Those travelling from southern Ontario to U.S. sites travelled most often by bus or car between 150 and $200 \mathrm{~km}$.

A limitation of this study is the response rate of $55.8 \%$, despite the one reminder phone call to participants. The response rate, however, did exceed that of most general mailed surveys conducted without reminder notices. A second limitation, as is the case with any mailed survey approach, is that those who returned the completed forms are likely to be individuals with an interest in the topic and are comfortable reading and responding to a survey. Unfortunately, data regarding educational level were not gathered during the study.

Despite study limitations, this is the first systematic exploration of a Canadian re-referral program for cancer patients receiving radiation treatment and it offers some interesting insights of benefit to the specific program managers as well as others who might be facing the necessity to develop a similar program. Overall, relatively high proportions of respondents indicated they were satisfied with their care. There were, however, specific areas where improvements could be made.

The decrease in satisfaction over time with coordination may have been influenced by two factors. The re-referral program enlarged dramatically through the fall (September-December) and winter

(January-March) months with significantly more patients wanting access to the program. Additional staff had to be hired and oriented to the program before service could be enhanced. During that interval, the existing staff was managing high caseloads and the timeline for their responses was compromised. Also during the winter months (January-March), travel in Canada is more difficult because of snow and ice. Outdoor activities are decreased, forcing people to remain indoors. Such a situation may have contributed to the boredom patients have reported experiencing while away from home receiving radiation treatment (Fitch et al., 2003).

Prior to treatment, many patients indicated they did not feel they had access to staff and support from the cancer centres near their homes. This is understandable, given many of these patients had not had appointments at the centres near their homes and did not know the oncologists or other staff. Those who did have an appointment would likely only have had one interaction which focused on the need to be treated elsewhere. Unless a patient was told specifically to take advantage of support services in the cancer centre, in all likelihood patients could gather an impression they were not able to use local services.

This pre-treatment interval marks the time when the diagnosis has been made and the individual is waiting for treatment to begin. Often, this is a time of high anxiety for patients when they fear the cancer is growing while they are waiting (Fitch et al., 2003). Also, it is a time when patients are not necessarily aware of the services that are available to assist them. Often, they learn about these services only after they have begun attending a cancer treatment centre (Degrasse \& Hugo, 1996). Improvements, then, could be made in the provision of information about services to these patients facilitating access to support services during the pre-treatment interval.

The provision of information about cancer, radiation treatment, and the cancer centre to which patients are being re-referred was also seen as needing improvement. The information issues existed for these patients prior to the beginning of their treatment. Once they arrived at the re-referral cancer centre and began their treatment, they were satisfied with the information they received. This observation raises questions about the nature of the conversations that are happening (or not) with the patients prior to their leaving home. Staff in local centres need to be alert to the information needs of patients entering the re-referral program. As well, the re-referral program may need to review the type of information and the timelines of

Table Four. Satisfaction with aspects of the re-referral program by gender

\begin{tabular}{|c|c|c|c|}
\hline \multirow[b]{2}{*}{ Items found to be significant } & \multicolumn{3}{|c|}{$\begin{array}{l}\text { Proportion of respondents in each group } \\
\text { who agreed with statement }\end{array}$} \\
\hline & Females & Males & Significance \\
\hline $\begin{array}{l}\text { It was clear to me that the decision to } \\
\text { travel to another city for radiation } \\
\text { treatment was my own, and that I had } \\
\text { the right to refuse. }\end{array}$ & $86 \%$ & $96 \%$ & $\begin{array}{c}\mathrm{df}=1 \\
\chi^{2}=6.08 \\
\mathrm{p}=0.025\end{array}$ \\
\hline $\begin{array}{l}\text { I received all the information I needed } \\
\text { about the steps required to arrange my } \\
\text { radiation in another city. }\end{array}$ & $71 \%$ & $88 \%$ & $\begin{array}{c}\mathrm{df}=1 \\
\chi^{2}=5.94 \\
\mathrm{p}=0.025\end{array}$ \\
\hline $\begin{array}{l}\text { My needs and those of my family/ } \\
\text { friends were taken into account when } \\
\text { arrangements were being made to travel } \\
\text { to another city. }\end{array}$ & $72 \%$ & $84 \%$ & $\begin{array}{c}\mathrm{df}=1 \\
\chi^{2}=4.2 \\
\mathrm{p}=0.05\end{array}$ \\
\hline $\begin{array}{l}\text { I was informed about services I might } \\
\text { need or desire, such as clinical } \\
\text { nutritionists, social workers, } \\
\text { pharmacists, chaplains, psychologists, } \\
\text { or support groups. }\end{array}$ & $65 \%$ & $78 \%$ & $\begin{array}{c}\mathrm{df}=1 \\
\chi^{2}=4.14 \\
\mathrm{p}=0.05\end{array}$ \\
\hline
\end{tabular}
forwarding that information to patients. However, given that issues were also cited regarding registration procedures at the cancer centre nearest the patient's home and the time available to talk, the question could be raised regarding what responsibility the staff members in the local cancer centres perceive they have for these patients. Staff members may well feel they have little responsibility for these patients, or the observations may reflect the heavy caseload and busy nature of the local clinics.

The provision of information about supportive care services was more of an issue for those receiving their care in the United States. Specific mechanisms were developed in the Canadian sites to provide this information. For example, an information session was held for patients once a week at the Thunder Bay site, co-facilitated by a social 
worker and a radiation therapist. Given the majority of patients sent to Canadian sites went to Thunder Bay, this information session may account for the differences between Canadian and U.S. centres. It would seem important for all centres accepting patients travelling for treatment to provide regular information sessions.

Fewer women than men were satisfied with several aspects of care related to arrangements and available services. The roles and responsibilities a woman carries will no doubt influence the degree of difficulty she might have in being away from home for a period of time. Many women need to make arrangements about household, family, and work responsibilities for the duration of the treatment interval. Despite being ill, women find they are still expected to care for children and household issues (Fitch, Bunston, \& Elliot, 1999) and they find it difficult to leave those responsibilities behind. For many, making these arrangements is another source of stress at a time when they are already feeling vulnerable. Women travelling for cancer treatment have described the worry they feel about the extra burden they are imposing upon their family with the alterations in responsibilities at home and the requests for a drive (Fitch et al., 2003). Similar kinds of concerns were described by rural Australian women who had to travel following their diagnosis for breast cancer (McGrath et al., 1999a, 1999b).

The differences in observations along gender lines could also reflect variation in general coping patterns. Recent work regarding self-help group experiences (Gray, Fitch, Davis, \& Phillips, 1997a, 1997b) has revealed interesting differences between men and women. For the most part, women turn to their network of family and friends for support. They are seeking an opportunity to discuss their feelings and talk about shared experiences. Their time with other patients in self-help groups focuses primarily on these objectives. Men, on the other hand, tend not to have elaborate networks of confidants (Gray, Fitch, Phillips, Labrecque, \& Fergus, 2000). Those with wives or partners may only talk with them about what is happening. Their experiences in self-help groups tend to focus on obtaining factual information. Given these differences, it may be more difficult for women to contemplate leaving home and their network of support to travel away for treatment. It may also mean there is a broad circle of social obligations that needs to be dealt with prior to leaving. Whether or not the women believe or feel they have the freedom to negotiate with the re-referral program staff may influence their sense of

\section{References}

Abbey-Livingstone, D. \& Associates. (1990). The needs of Ontario cancer patients: An assessment 1990. Toronto: Canadian Cancer Society.

Canadian Cancer Society. (1992). Final report on the needs of people living with cancer across Canada. Toronto: Author.

Carroll-Johnson, R.M., Gorman, L.M., \& Bush, M.J. (1998). Psychosocial nursing care along the cancer continuum. Pittsburgh, PA: Oncology Nursing Press.

Davis, C., \& Girgis, A. (1998). Needs assessment of rural and remote women travelling to the city for breast cancer treatment. Australia and New Zealand Journal of Public Health, 22(5), 525-527.

Degrasse, C., \& Hugo, K. (1996). Supportive care needs of women undergoing breast diagnostics and their families: A focus on nursing interventions. Canadian Oncology Nursing Journal, 6(4), 185-190.

Fitch, M.I., Bunston, T., \& Elliot, M. (1999). When Mom's sick: Changes in a mother's role and in the family after her diagnosis of cancer. Cancer Nursing, 22(1), 58-63.

Fitch, M.I., Gray, R.E., McGowan, T., Brunskill, I., Steggles, S., Sellick, S . et al., (2003). Travelling for radiation cancer treatment: Patient perspectives. Psycho-Oncology, 12, 664-694.

Given, B.A., Given, C.W., \& Harlan, A.N. (1994). Strategies to meet whether or not their needs were taken into account when arrangements for travel were being made.

Concerns about financial issues also need to receive attention. Where there is a reimbursement process, patients need to be informed about it and understand how the reimbursement is handled and exactly what items are covered. An assessment ought to be made about the person's ability to pay for items initially and await reimbursement at a later time. Some individuals find paying for items initially themselves creates a difficult cash flow situation.

Finally, these patients who have been treated in a cancer centre away from home indicated a lack of confidence about their follow-up care upon their return home. During treatment, when a patient sees members of a care team on a daily basis, a trusting relationship grows as the interactions occur. To see a health care practitioner for followup care who was not a part of this treatment experience means going to someone the patient does not know and with whom there has been no opportunity to form a trusting relationship. Additionally, if the steps in the process for follow-up care are not clear, this could contribute to patients feeling a lack of confidence about how that care will be managed. Information about the process for follow-up care needs to be made clear for the patient, including who to call if there are problems with side effects of treatment. Also, the first visit to the local cancer centre nearest the patient's home may need to be longer than a usual follow-up appointment to allow for dialogue about the patient's experience of receiving treatment away from home and facilitate the establishment of a trusting relationship.

\section{Implications for oncology nurses}

There are several implications for nurses who are caring for patients who travel for their radiation treatment. Prior to going away from home, patients would benefit from information about travel arrangements, financial support, support programs, and the location and cancer centre to which they are travelling. Knowing about support programs available in their own community and who they can call for help would be useful to patients both during and after their course of treatment. For patients returning to a cancer centre near their home following treatment away from home, nurses need to be particularly sensitive to the notion that patients will have questions about their follow-up care and may lack confidence in the care team. Efforts are needed to build a trusting relationship with these individuals.

the needs of the rural poor. Seminars in Oncology Nursing, 10(2), 114-122.

Gray, R.E., Fitch, M., Davis, C., \& Phillips, C. (1997b). Interviews with men about their self-help experiences. Journal of Palliative Care, 13(1), 15-21.

Gray, R.E., Fitch, M., Davis, C., \& Phillips, C. (1997a). A qualitative study of breast cancer self-help groups. Journal of Psychosocial Oncology, 6, 279-289.

Gray, R.E., Fitch, M., Phillips, C., Labrecque, M., \& Fergus, K. (2000). Managing the impact of illness: The experiences of men with prostate cancer and their spouses. Journal of Health Psychology, 5(4), 531-548.

McGrath, P., Patterson, C., Yates, P., Treloars, S., Oldenburg, B., \& Loos, C. (1999a). A study of post-diagnosis breast cancer concerns for women living in rural and remote Queensland (Part I): Personal concerns. Australian Journal of Rural Health, 7, 34-42.

McGrath, P., Patterson, C., Yates, P., Treloars, S., Oldenburg, B., \& Loos, C. (1999b). A study of post-diagnosis breast cancer concerns for women living in rural and remote Queensland (Part II): Support issues. Australian Journal of Rural Health, 7, 43-52. 